\title{
Tracheal Secretion Management in the Mechanically Ventilated Patient: Comparison of Standard Assessment and an Acoustic Secretion Detector
}

\author{
Alberto Lucchini RN, Alberto Zanella MD, Giacomo Bellani MD, Roberto Gariboldi RN, \\ Giuseppe Foti MD, Antonio Pesenti MD, and Roberto Fumagalli MD
}

\begin{abstract}
BACKGROUND: Standard indications for endotracheal suctioning are often based on clinical judgment on the deterioration of the patient's condition, and/or routine suctioning. TBA Care is a secretion detector that analyses airway sounds and indicates the need for suctioning. OBJECTIVE: To determine the efficacy of TBA Care in detecting retained secretions, compared to standard indications. METHODS: We conducted a prospective randomized trial with 72 general intensive care unit patients randomized at intubation into 2 groups, differing only in suctioning indications. The control group indications were at least 3 scheduled suctionings per day or were clinically driven. The secretion-detector group indications were device signal or clinically driven. At each suctioning session we recorded the indication for suctioning and the amount of secretions removed. Patients were followed until intensive care unit discharge or extubation. Diagnosis of ventilatorassociated pneumonia was confirmed via microbiological analysis of suctioned secretions. RESULTS: We analyzed 1,705 suctionings in the control group and 1,354 in the secretion-detector group. The secretion-detector group had fewer suctionings per day $(3.9 \pm 2.3$ vs $4.8 \pm 1.2, P=.002)$ and a lower rate of unnecessary suctionings $(4 \% \mathrm{vs} 12 \%, P<.001)$. In the secretion-detector group, $97 \%$ of the suctionings were performed following the signal from the TBA Care device. In the control group, clinical deterioration $(65 \%)$ was the most frequent indication for suctioning. The incidence of ventilator-associated pneumonia was similar in the groups. CONCLUSIONS: TBA Care seems to give valid and timely indications for suctioning, anticipating clinical deterioration due to secretion retention and reducing unnecessary suctionings. (ClinicalTrials.gov registration NCT00932776.) Key words: mechanical ventilation; endotracheal suctioning; secretion detector; secretion management; ventilator-associated pneumonia. [Respir Care 2011;56(5):596-603. (C) 2011 Daedalus Enterprises]
\end{abstract}

\section{Introduction}

The lower respiratory tract of healthy humans is normally kept sterile by natural defense mechanisms: airway barriers, mucociliary clearance, and cough. Endotracheal intubation and mechanical ventilation, which are life-sav-

\footnotetext{
Alberto Lucchini RN, Giacomo Bellani MD, Roberto Gariboldi RN Giuseppe Foti MD, Antonio Pesenti MD, and Roberto Fumagalli MD are affiliated with the Department of Perioperative Medicine and Intensive Care, San Gerardo Hospital, Monza, Italy. Alberto Zanella MD is affiliated with the Department of Experimental Medicine, University of Milan-Bicocca, Monza, Italy. Drs Bellani, Pesenti, and Fumagalli are also affiliated with the Department of Experimental Medicine, University of Milan-Bicocca, Monza, Italy.
}

Mr Lucchini and Dr Zanella are co-first authors of this paper. ing procedures in patients with respiratory insufficiency, profoundly impair these defensive mechanisms, increasing the risk of bacterial colonization and ventilator-associated

\footnotetext{
Alberto Lucchini RN presented a version of this paper at the Simposio Mostra Anestesia Rianimazione e Terapia Intensiva, held May 6-8, 2009, in Milan, Italy.

The authors have disclosed no conflicts of interest.

Correspondence: Roberto Fumagalli MD, Unità Operativa Complessa, Anestesia, e Rianimazione Azienda, Ospedaliera San Gerardo di Monza, Via Pergolesi 33-20052 Monza MI Italia. E-mail: roberto.fumagalli@ unimib.it.
}

DOI: $10.4187 /$ respcare.00909 
pneumonia (VAP). ${ }^{1,2}$ The endotracheal tube cuff, which allows positive-pressure ventilation and prevents aspiration, compromises mucociliary clearance by mechanically blocking mucus flow toward the oropharynx. ${ }^{3,4}$ Retained mucus in the lower airways must therefore be removed by endotracheal suctioning to prevent accumulation and consequent complications (airway obstruction, increased work of breathing, deterioration of gas exchange, and hemodynamic instability). ${ }^{5}$ Although endotracheal suctioning is a standard of care in all mechanically ventilated patients, clear guidelines regarding the technique and timing of suctioning are lacking. The applicable American Association for Respiratory Care (AARC) guideline ${ }^{6}$ suggests that endotracheal suctioning should be performed at some minimum frequency or when clinically indicated (ie, when complications due to accumulated secretions are manifested). Since endotracheal suctioning can cause hypoxemia, mechanical trauma, bronchospasm, and hemodynamic instability, an accurate assessment of the need for suctioning might decrease the frequency of suctioning complications. TBA Care (First Medica, Cusago, Italy) is a novel device designed to generate a signal when secretions are present in the respiratory tract of an intubated patient, indicating the need for endotracheal suctioning.

Strategies to detect retained secretions in intubated patients have been examined in very few studies..$^{7-9}$ To the best of our knowledge, this is the first prospective randomized trial to compare different indications for endotracheal suctioning. We compared the efficacy of TBA Care in detecting the presence of secretions in the airways to standard indications, and we tested the hypothesis that different suctioning indications could impact the incidence of $\mathrm{VAP}^{2,10-12}$ and extubation rate.

\section{Methods}

This study was performed in the Department of Perioperative Medicine and Intensive Care, San Gerardo Hospital, Monza, Italy, and approved by our hospital's ethics committee. Informed consent was obtained from all the patients.

\section{Patients}

We enrolled, over a 9-month period, 72 intubated and mechanically ventilated adult patients in our general intensive care unit (ICU). Inclusion criteria were: age $>18$ years, endotracheal intubation or tracheostomy tube, and expected duration of ventilation $>48$ hours. Exclusion criteria were: age $<18$ years, pregnancy, and active bronchial bleeding.

After enrollment and collection of baseline variables, patients were randomly assigned to the control group or to the secretion-detector group, and stratified according to clinical suspicion of pneumonia, following 2 separate printed randomization lists for each stratum. Criteria for clinical suspicion of pneumonia on admission were based on the applicable American Thoracic Society guideline: presence of a new or progressive radiographic infiltrate plus at least two of the following: temperature $>38^{\circ} \mathrm{C}$, leukocytosis or leucopenia, or purulent secretions. ${ }^{13}$

\section{Endotracheal Suctioning}

In all the patients we used a 12 French closed suctioning system (Ballard, Kimberly-Clark Health Care, Zaventem, Belgium), which we replaced every 72 hours, in accordance with the manufacturer's recommendations. The suctioning system was connected to a wall suction port regulated at $80 \mathrm{~mm} \mathrm{Hg}$. The endotracheal tube cuff was inflated to $30 \mathrm{~cm} \mathrm{H}_{2} \mathrm{O}$ and checked 4 times a day.

The 2 groups differed only in the indications for suctioning (see below). The groups received the same clinical management and identical measures for VAP prevention: semi-recumbent position, continuous enteric nutrition, stress ulcer prophylaxis, and mechanical ventilation weaning protocol. With all the patients we used a heated humidifier (DAR HC 2000, Covidien) for the entire study period.

Patients in the control group were suctioned following our secretion-management protocol, which is based on the AARC clinical practice guideline. ${ }^{6}$ Patients are suctioned at least 3 times a day (scheduled suctionings, one per nursing shift) or if a clinical sign attributable to secretion retention is evident: coarse breath sounds on auscultation, dyspnea, cough, apparent increased work of breathing, increased inspiratory peak pressure during volume controlled ventilation, decreased tidal volume during pressure-controlled ventilation, $\mathrm{S}_{\mathrm{pO}_{2}}$ decrease not otherwise explained, or visible secretions in the endotracheal tube or ventilator circuit.

In the study group, secretions were monitored with the TBA Care system, and the decision to suction was based on the signal from the TBA Care system and/or the indications recommended in the AARC clinical practice guideline.

\section{Data Collection}

Immediately after each suctioning we recorded the day and time, the indication for the suctioning, the number of suction catheter passes, and the quantity of secretions collected, which we rated with a semi-quantitative system for categorizing the amount of secretions collected: $0=$ none (we deemed these unnecessary suctionings), $1=$ scarce, $2=$ few, $3=$ moderate, $4=$ abundant. To standardize the secretion-quantity scoring, prior to the study all the nurses 


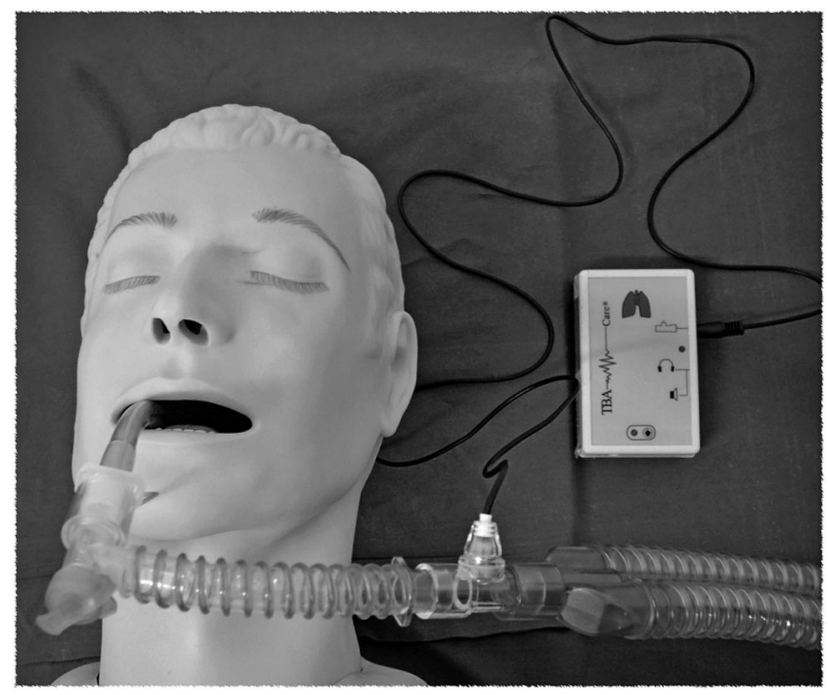

Fig. 1. The TBA Care acoustic secretion detector module connects to a sensor at the $\mathrm{Y}$-piece. When secretions are detected in the airway the module generates an acoustic and visual signal.

were trained in the semi-quantitative system, with in vitro simulations of the suctioning procedure, and known volumes of blue dye. The daily secretion volume was defined as the sum of the scores from that day's suctionings.

We also recorded the number of suctioning passes in each suctioning session. Each suctioning session consisted of 1,2 , or 3 suctioning passes with the closed suctioning system. If further suctioning was deemed necessary, open suctioning was performed. The decision to perform more than one suctioning pass was based on clinical judgment in the control group, and on the TBA Care device's signal in the secretion-detector group.

Patients were followed until either ICU discharge, extubation, tracheostomy, or death. If VAP was clinically suspected (per the applicable American Thoracic Society guidelines ${ }^{13}$ ), we sent suctioned secretions for quantitative microbiologic assay, which was considered positive with $\geq 10^{6}$ colony-forming units per $\mathrm{mL}$. Microbiologic assay was also performed during the first 48 hours of ventilation. VAP was treated according to the applicable American Thoracic Society guidelines. ${ }^{13}$

\section{TBA Care System}

The TBA Care device is an acoustic monitor of tracheobronchial secretions (Fig. 1). The disposable sensor attaches to the circuit at the Y-piece. TBA Care allows noninvasive bedside monitoring of airway secretions in intubated and tracheotomized patients, and the patient may or may not be ventilator-dependent. The TBA Care device generates an acoustic and visual signal when it detects secretions in the airway, suggesting the need for suction- ing. During the study we changed the sensor every 3 days, per the manufacturer's recommendation.

\section{Outcomes}

Our primary outcome of interest was whether the TBA Care device reduced the number of unnecessary suctionings. The secondary outcomes were the total number of suctionings, number of suctioning passes, incidence of VAP, and extubation rate.

\section{Statistics}

Sample size was computed taking into account an incidence of unnecessary suctionings of approximately $15 \% .{ }^{14}$ To detect a $10 \%$ reduction in the incidence of suctioning, with a type I error of 0.05 and a power of 0.9 , 915 suctionings were necessary in each arm. Based on a preliminary report ${ }^{14}$ that estimated an average of 25 suctionings per patient per ICU stay, we computed a need for 36 patients in each arm. Statistical analysis was performed with statistics software (PASW Statistics 18, SPSS, Chicago, Illinois). Categorical variables were compared with chisquare tests, and if statistical significance was detected, post-hoc comparison between the secretion-detector group and the control group was performed with the Z-test. Nonparametric variables were compared with the Mann-Whitney $\mathrm{U}$ test or Wilcoxon test, where appropriate. We used log-rank sets to compare the extubation rates. $P<.05$ was considered statistically significant.

\section{Results}

From August 2006 to April 2007, 335 patients were admitted to our 8-bed general ICU. Seventy-two patients were enrolled in the study: 36 in the control group, and 36 in the secretion-detector group. Eleven patients $(31 \%)$ in each group were admitted with a clinical suspicion of pneumonia (Fig. 2). Table 1 describes the subjects.

We recorded 3,198 suctionings: 1,832 in the control group and 1,366 in the secretion-detector group, over a study period of 415 days and 388 days, respectively. One hundred-thirty-nine suctionings $(4 \%)$ were removed from the analysis due to missing data, so we analyzed 1,705 suctionings in the control group and 1,354 in the secretiondetector group.

The collected secretion volume per suctioning session significantly differed between the 2 groups (Fig. 3). In particular, the number of suctionings that collected no secretions (unnecessary suctionings) was $4 \%$ in the secretion-detector group and $12 \%$ in the control group $(P<.001)$. In the secretion-detector group there were 47 unnecessary suctionings (Fig. 4), and 27 (56\%) of those were made on the basis of clinical deterioration or auscultation, although 


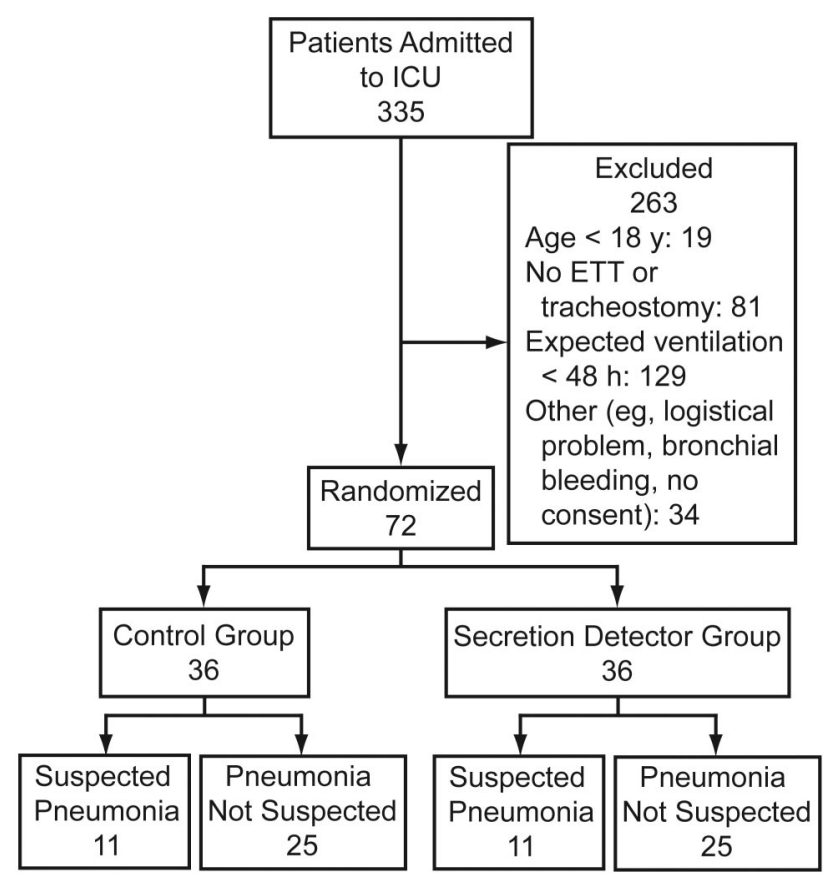

Fig. 2. Flow chart.

Table 1. Demographic and Clinical Data at Enrollment*

\begin{tabular}{|c|c|c|}
\hline & $\begin{array}{l}\text { Secretion } \\
\text { Detector } \\
\text { Group }\end{array}$ & $\begin{array}{l}\text { Control } \\
\text { Group }\end{array}$ \\
\hline Age (y) & $70 \pm 12$ & $63 \pm 16$ \\
\hline SAPS II score & $51.3 \pm 15.3$ & $55.9 \pm 15.9$ \\
\hline $\mathrm{P}_{\mathrm{aO}_{2}} / \mathrm{F}_{\mathrm{IO}_{2}}(\mathrm{~mm} \mathrm{Hg})$ & $199 \pm 81$ & $221 \pm 113$ \\
\hline \multicolumn{3}{|l|}{ Pneumonia on Admission } \\
\hline Suspected & 11 & 11 \\
\hline Confirmed & 7 & 7 \\
\hline Female-to-male ratio $(\%)$ & 31 & 31 \\
\hline COPD $(n)$ & 8 & 5 \\
\hline Smoker $(n)$ & 8 & 9 \\
\hline \multicolumn{3}{|l|}{ Admission Diagnosis } \\
\hline Medical & 25 & 23 \\
\hline Pulmonary causes & 16 & 16 \\
\hline Cardiovascular causes & 2 & 3 \\
\hline Sepsis & 7 & 5 \\
\hline Surgical & 11 & 13 \\
\hline
\end{tabular}

the TBA Care device did not indicate airway secretions. Therefore, only 20 suctionings (2\%) of the 1,318 indicated by the secretion detector were unnecessary. The positive predictive value of the TBA Care device was $99 \%$. In the control group, of the 207 unnecessary suctionings, 159 (76\%) were scheduled suctionings. In the secretion-detec-

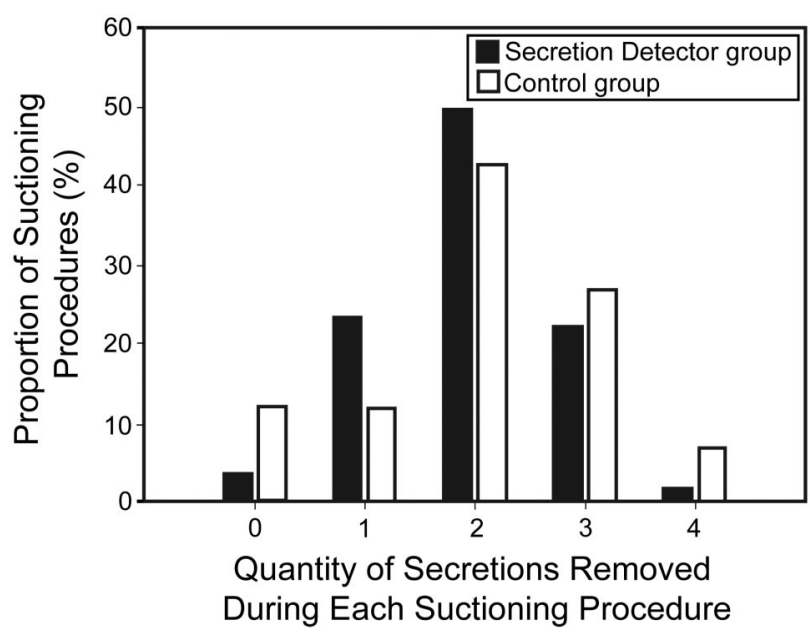

Fig. 3. Secretions collected during endotracheal suctioning, measured with a semi-quantitative method. $0=$ no secretions collected (unnecessary suctioning), $1=$ scarce, 2 = few, $3=$ moderate, $4=$ abundant. All the difference are statistically significant.

tor group, collection of no or scare secretions per suctioning session was more frequent, whereas in the control group collection of moderate or abundant secretions was more common (see Fig. 3).

Suctioning indications significantly differed between the 2 groups (Fig. 5). In the secretion-detector group, 97\% of the suctionings were performed following the TBA Care device's signal, $2 \%$ were due to clinical deterioration, and less than $1 \%$ were due to auscultation findings. In the control group the main reason for suctioning was dyspnea (53\%). Suctionings prompted by clinical deterioration were more frequent in the control group than in the secretiondetector group (65\% vs $2 \%, P=.01)$. Scheduled suctionings in the control group were 380 (22\%).

Figure 6 shows the number of suctioning passes. A single closed suctioning pass was more frequent in the secretion-detector group than in the control group, whereas multiple suctioning passes were more frequent in the control group.

There was a significant difference between the average number of suctioning passes per patient per day: $5.9 \pm 6.5$ in the secretion-detector group, and $9.3 \pm 2.9$ in the control group $(P=.01)$. Table 2 shows the suctioning frequencies and secretion volumes collected, considering the mean value of each patient throughout the study period. Patients in the secretion-detector group were suctioned less frequently and had fewer suctioning passes. The daily average volume of secretions collected was higher in the control group, but there were no significant differences in the average volume of secretions collected per suctioning session or duration of ventilation. Since the presence of scheduled suctionings in the control group might have increased the number of suctionings, we performed a post- 


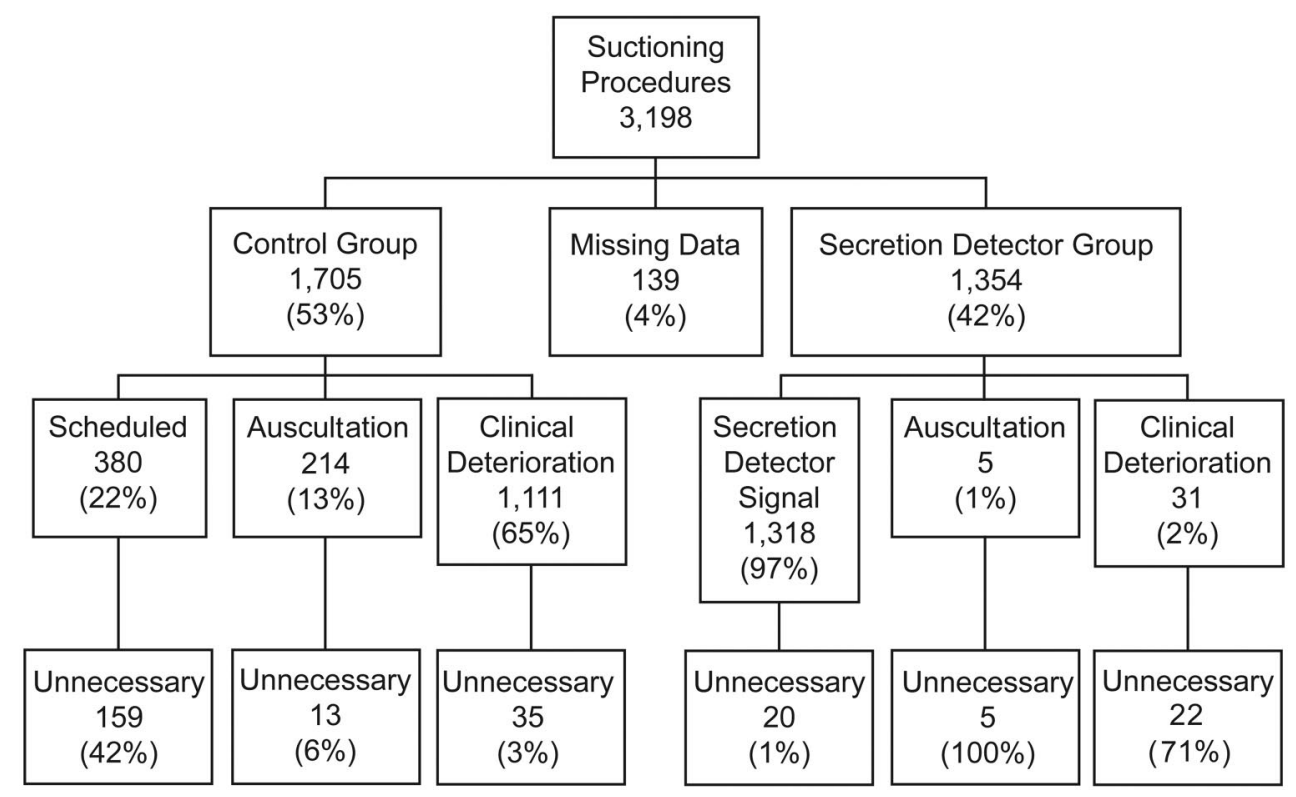

Fig. 4. Indications for the suctionings that collected no secretions.

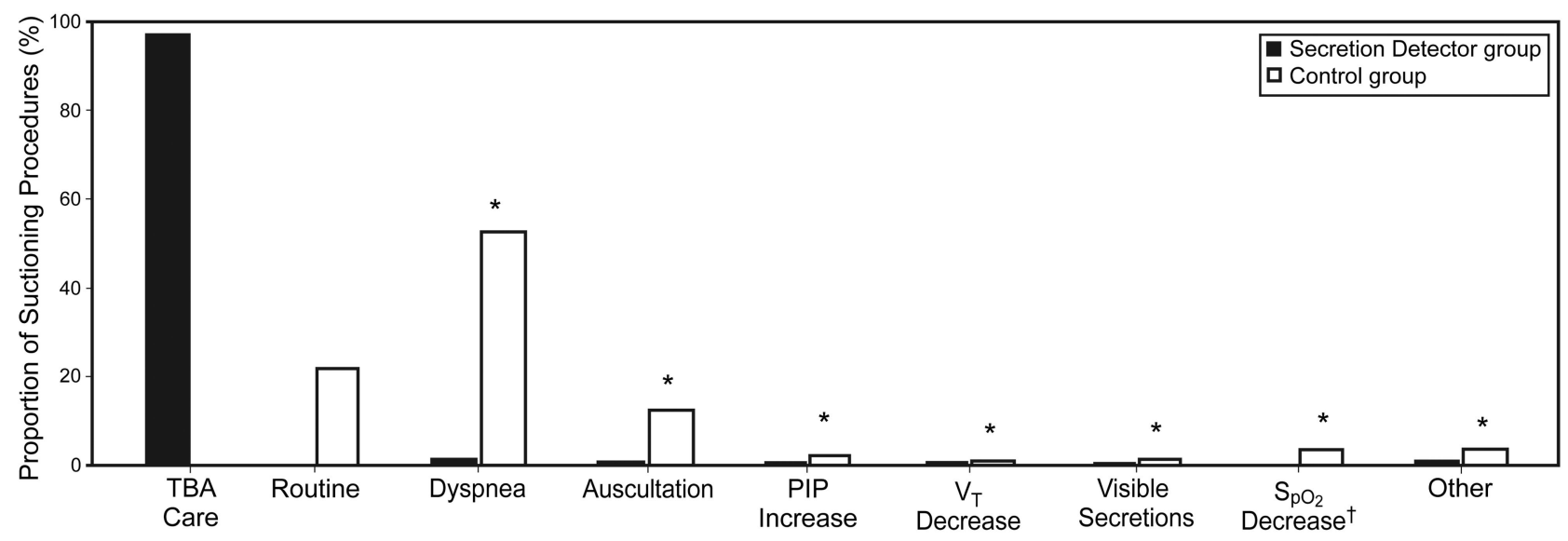

Fig. 5. Indications for all the suctionings. Routine = scheduled suctioning, which occurred only in the control group, once per shift (ie, at least 3 times a day). Dyspnea = dyspnea or cough or apparent increased work of breathing Auscultation = coarse breath sounds on auscultation. $>$ PIP $=$ increased peak inspiratory pressure during volume controlled or pressure controlled volume guaranteed ventilation. $<\mathrm{V}_{\mathrm{T}}=$ decreased tidal volume during pressure controlled ventilation. Visible secretions = visible secretions in the endotracheal tube or ventilator circuit. $<\mathrm{S}_{\mathrm{pO}_{2}}=\mathrm{S}_{\mathrm{pO}_{2}}$ decrease not otherwise explained. Other = clinical reasons other than the previous. In all the categories the difference was significant.

hoc analysis by removing the scheduled suctionings from the analysis (Table 3). With the scheduled suctionings removed, the percent of unnecessary suctionings was $4 \%$ in both groups. Overall, the collected secretion volume was lower in the secretion-detector group, as shown by the higher rate of no secretions collected, whereas in the control group collection of moderate or abundant secretions was more frequent. The volume collected in each suctioning session was higher in the secretion-detector group, whereas the daily volume of secretions collected was not significantly different.
The indication for suctioning and number of suctioning passes did not significantly change after removing the scheduled suctionings from the control group. Survival analysis for extubation showed no significant differences between the 2 groups (Fig. 7). The mortality rate was $25 \%$ (9 patients) in both groups. Clinical suspicion of pneumonia at randomization was microbiologically confirmed in 7 patients per group. VAP was diagnosed in 6 patients in the control group and 3 in the secretion-detector group $(P=.27)$. We found no major complications related to the use of TBA Care device. 


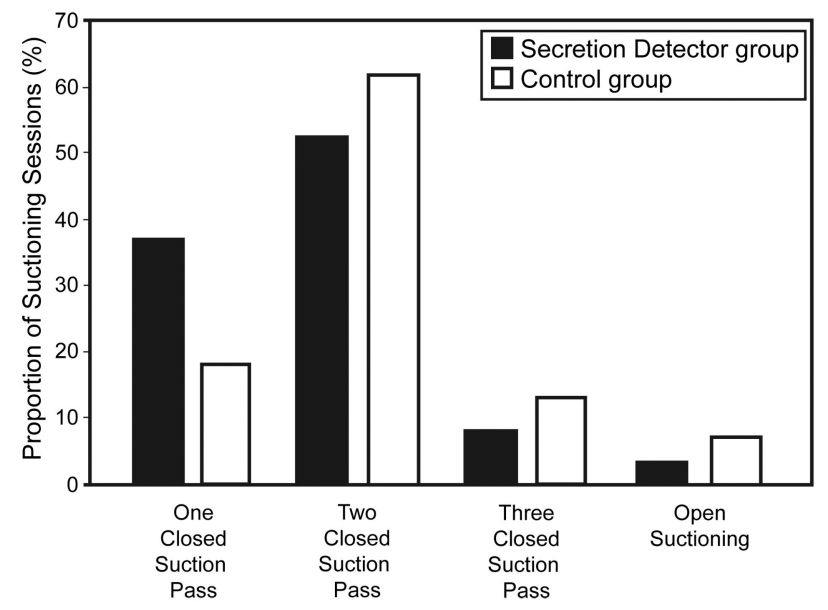

Fig. 6. Number of suctioning passes. The first 1,2 , or 3 passes were always with the closed suctioning system. If more than 3 passes were required, the operator changed to the open suctioning system. All the difference are statistically significant.

\section{Discussion}

Endotracheal suctioning is a primary component of secretion management in mechanically ventilated patients. For many years, endotracheal suctioning has been the broad title given to all aspects of this procedure. Most studies concerning airway suctioning have been dedicated to its mechanics and complications. ${ }^{15-19}$ While the question of when to suction remains unanswered, ${ }^{20-22}$ some authors ${ }^{8,9}$ have suggested that analysis of ventilator curves might predict the presence of retained secretions, whereas Branson, in a review on secretion management, highlighted the need for more reliable detection methods. ${ }^{20}$ In a recent editorial, Marini referred to acoustic monitoring of airway sounds to improve the timing of suctioning and to avoid unnecessary suctioning and the related risks. ${ }^{23}$

We compared an acoustic secretion detector to our usual protocol, which follows the indications of the AARC clinical practice guideline and involves scheduled suctioning plus clinical assessment of the need for suctioning. ${ }^{6}$ Our control group had a higher rate of suctioning sessions, suctioning passes per day, and unnecessary suctionings. More than $76 \%$ of those unnecessary suctionings were scheduled suctionings. This result highlights the potentially harmful effects of scheduled suctioning in the absence of signs of secretion retention. However, while $42 \%$ of the scheduled suctionings collected no secretions, $58 \%$ of the scheduled suctionings collected some secretions.

Our use of scheduled suctioning in the control group was carefully considered during the planning of the study. The first factor we considered was that the standard indications for suctioning rely mainly on the deterioration of the patient's condition, so they are vague, nonspecific, and/or late. The second factor was that in the absence of signs of deterioration, how long can suctioning be safely withheld?24 It is for these reasons that we used 3 scheduled suctionings per day, as recommended in the AARC guideline: "Endotracheal suctioning may be required at some minimum frequency in order to maintain the patency of the artificial airway used." The scheduled suctionings were performed only if no suctioning had otherwise occurred during that nursing shift. In doing this our aim was to monitor the sensitivity of the standard indications. Fiftyeight percent of the scheduled suctionings collected secretions, which highlights the high quantity of missed suctionings following standard protocol indications. Table 3 shows the post-hoc analysis of the suctioning frequencies and volumes of secretions collected, with the scheduled suctionings excluded from the analysis. Note, however, that this analysis does not represent what would have happened if scheduled suctionings had not been included in the protocol; in fact, most likely, the $58 \%$ of the scheduled suctionings that removed some secretions would probably have been conducted due to a clinical indication.

The poor sensitivity of the standard indications (auscultation and clinical signs) is also supported by the larger amount of secretions collected per suctioning in the control group, which, on the other hand, seems to indicate the need for suctioning when the secretions are not yet causing clinical signs. These results may suggest that earlier secretion detection with the secretion detector might reduce the rate of complications related to tracheal secretion retention. If we analyze the indications for suctioning (see Fig. 5), it is evident that in the secretion-detector group almost all the suctionings were performed following the secretion-detector signal. The low rate of indications for suctioning other than the secretion detector (ie, clinical signs of secretion retention) suggests that the TBA Care has a high sensitivity in detecting secretions. In fact, we speculate that if the secretion detector was not sensitive for early secretion detection, we would have found a much higher rate of indications due to secretion-retention-related complications. Furthermore, the secretion-detector group had an extremely low rate of unnecessary suctionings and fewer suctioning passes, which means that the secretion detector reliably indicated when to stop suctioning.

The higher number of suctionings and passes and the higher volume of retained secretions in the control group may have led to greater irritation of the airways mucosa and consequent higher mucus production, which may explain the higher volume of secretions per day in the control group.

\section{Limitations}

It was not possible to blind the operators during the suctionings, and our system for categorizing secretion vol- 
Table 2. Suctioning Frequencies and Volumes of Secretions Retrieved

\begin{tabular}{|c|c|c|c|c|c|c|c|}
\hline & \multicolumn{3}{|c|}{ Secretion Detector Group } & \multicolumn{3}{|c|}{ Control Group } & \multirow{2}{*}{$P$} \\
\hline & Mean \pm SD & Median & $\mathrm{IQR}$ & Mean \pm SD & Median & IQR & \\
\hline Days of mechanical ventilation & $10.7 \pm 11.6$ & 6.0 & $4.0-11.0$ & $11.2 \pm 9.1$ & 8.2 & $4.0-17.2$ & .43 \\
\hline Suctioning sessions per day & $3.9 \pm 2.3$ & 3.7 & $2.1-4.5$ & $4.8 \pm 1.2$ & 4.5 & $4.1-5.2$ & .002 \\
\hline Suctioning passes per day & $5.9 \pm 6.5$ & 6.0 & $3.9-8.0$ & $9.3 \pm 2.9$ & 9.6 & $7.7-12.0$ & $<.001$ \\
\hline Volume of secretions per day* & $7.7 \pm 5.3$ & 6.7 & $3.0-9.1$ & $9.7 \pm 3.5$ & 7.5 & $5.1-11.0$ & .01 \\
\hline Volume of secretions per suctioning* & $1.9 \pm 0.4$ & 1.8 & $1.6-2.2$ & $2.0 \pm 0.5$ & 2.3 & $2.0-2.7$ & .28 \\
\hline
\end{tabular}

Table 3. Suctioning Frequencies and Volumes of Secretions Retrieved, With the Scheduled Suctionings Excluded From the Analysis

\begin{tabular}{lccc}
\hline \hline & $\begin{array}{c}\text { Secretion Detector } \\
\text { Group } \\
\text { (mean } \pm \text { SD) }\end{array}$ & $\begin{array}{c}\text { Control } \\
\text { Group } \\
\text { (mean } \pm \text { SD) }\end{array}$ & $P$ \\
\hline Suctioning sessions per day & $3.9 \pm 2.3$ & $3.9 \pm 1.4$ & .65 \\
$\begin{array}{l}\text { Suctioning passes per day } \\
\text { Volume of secretions per }\end{array}$ & $5.9 \pm 6.5$ & $7.5 \pm 2.9$ & .059 \\
$\quad$ day* & $7.7 \pm 5.3$ & $8.6 \pm 3.2$ & .12 \\
$\begin{array}{l}\text { Volume of secretions per } \\
\text { suctioning* }\end{array}$ & $1.9 \pm 0.4$ & $2.2 \pm 0.5$ & .002 \\
& & &
\end{tabular}

* These values are on a $0-4$ scale: $0=$ none, $1=$ scare, $2=$ few, $3=$ moderate, $4=$ abundant.

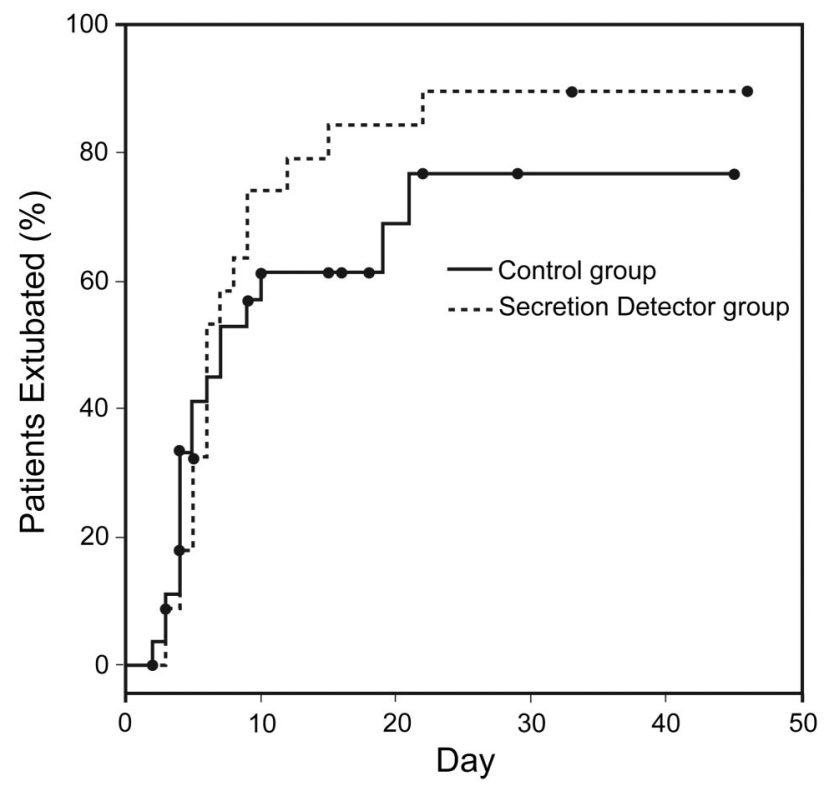

Fig. 7. Survival to extubation.

ume (none to abundant) was subjective. However, all the operators were trained in our semi-quantitative system for categorizing the amount of secretions collected. We did not record complications due to suctionings, so foreseeing a clinical advantage in avoiding one (out of five) suctionings per day, although reasonable, is debatable. The difference in the number of suctioning passes per day was more striking: 5.9 versus 9.3. Patients recall endotracheal suctioning as painful, ${ }^{25}$ so reducing the number of suctioning passes should decrease patient discomfort.

During intubation and ventilation the patient is at risk for lower respiratory tract infection because anatomical airway barriers and mucociliary clearance are impaired. ${ }^{4}$ In particular, mucus drainage from the lower airways is impaired and mucus tends to accumulate in the proximal trachea, requiring suctioning. ${ }^{3}$ Timely suctioning is critical, since delay can lead to excessive accumulation of airway secretions, which, experimental studies show, may backflow into the lung and cause infection. ${ }^{3}$ Since the purpose of the secretion detector is to indicate the presence of secretions in a timely manner, we speculated that the TBA Care might reduce the incidence of VAP. However, we found no significant difference in the incidence of VAP, despite the fact that one might reason that secretion detector error misjudging the ideal suctioning frequency would result in a lower rate of suctioning per day in the secretion-detector group, and eventually lead to a higher volume of retained secretions and a consequent higher risk of VAP. Future studies, with a larger patient population, are required to further evaluate the influence of the secretion detector on the incidence VAP.

\section{Conclusions}

Endotracheal suctioning is necessary to remove airway secretions and maintain airway patency. Even though it is routinely performed several times a day, clear indications for suctioning are lacking, and the available indications are based on deterioration of the patient's condition due to secretion retention. ${ }^{7,8}$ TBA Care seems to provide reliable indication of the need for suctioning. Its continuous airway monitoring allows suctioning prior to clinical deterioration caused by secretion retention, reduces unnecessary suctionings, and reduces the number of suctioning passes. 


\section{Standard Tracheal Secretion Assessment Versus an Acoustic Secretion Detector}

\section{REFERENCES}

1. Safdar N, Crnich CJ, Maki DG. The pathogenesis of ventilatorassociated pneumonia: its relevance to developing effective strategies for prevention. Respir Care 2005;50(6):725-739; discussion 739741.

2. Craven DE, Chroneou A, Zias N, Hjalmarson KI. Ventilator-associated tracheobronchitis the impact of targeted antibiotic therapy on patient outcomes. Chest 2009;135(2):521-528.

3. Bassi GL, Zanella A, Cressoni M, Stylianou M, Kolobow T. Following tracheal intubation, mucus flow is reversed in the semirecumbent position: possible role in the pathogenesis of ventilatorassociated pneumonia. Crit Care Med 2008;36(2):518-525.

4. Sackner MA, Hirsch J, Epstein S. Effect of cuffed endotracheal tubes on tracheal mucous velocity. Chest 1975;68(6):774-777.

5. American Association for Respiratory Care. Clinical practice guideline. Endotracheal suctioning of mechanically ventilated patients with artificial airways: 2010. Respir Care 2010;55(6):758-764.

6. American Association for Respiratory Care. Clinical practice guideline. Endotracheal suctioning of mechanically ventilated adults and children with artificial airways. Respir Care 1993;38(5):500-504.

7. Amborn SA. Clinical signs associated with amount of tracheobronchial secretions. Nurs Res 1976;25(2):121-126.

8. Guglielminotti J, Alzieu M, Maury E, Guidet B, Offenstadt G. Bedside detection of retained tracheobronchial secretions in patients receiving mechanical ventilation: is it time for tracheal suctioning? Chest 2000;118(4):1095-1099.

9. Jubran A, Tobin MJ. Use of flow-volume curves in detecting secretions in ventilator-dependent patients. Am J Respir Crit Care Med 1994;150(3):766-769.

10. Cook D, Ricard JD, Reeve B, Randall J, Wigg M, Brochard L, et al. Ventilator circuit and secretion management strategies: a FrancoCanadian survey. Crit Care Med 2000;28(10):3547-3554.

11. Estes RJ, Meduri GU. The pathogenesis of ventilator-associated pneumonia. 1. Mechanisms of bacterial transcolonization and airway inoculation. Intensive Care Med 1995;21(4):365-383.

12. Niel-Weise BS, Snoeren R, van den Broek PJ. Policies for endotracheal suctioning of patients receiving mechanical ventilation: A sys- tematic review of randomized controlled trials. Infect Control Hosp Epidemiol 2007;28(5):531-536.

13. Guidelines for the management of adults with hospital-acquired, ventilator-associated, and healthcare-associated pneumonia. Am J Respir Crit Care Med 2005;171(4):388-416.

14. Lucchini A, Asnaghi E, Doni V, Pelucchi S, Villa S, Tundo P, et al. When to perform endotracheal suctioning: new technology for diagnosis. Minerva Anestesiol 2006;72(Suppl 1):6-7. Article in Italian.

15. Johnson KL, Kearney PA, Johnson SB, Niblett JB, MacMillan NL, McClain RE. Closed versus open endotracheal suctioning: costs and physiologic consequences. Crit Care Med 1994;22(4):658-666.

16. Shah S, Fung K, Brim S, Rubin BK. An in vitro evaluation of the effectiveness of endotracheal suction catheters. Chest 2005;128(5): 3699-3704.

17. Van de Leur JP, Zwaveling JH, Loef BG, Van der Schans CP. Endotracheal suctioning versus minimally invasive airway suctioning in intubated patients: a prospective randomised controlled trial. Intensive Care Med 2003;29(3):426-432.

18. Vanner R, Bick E. Tracheal pressures during open suctioning. Anaesthesia 2008;63(3):313-315.

19. Cereda M, Villa F, Colombo E, Greco G, Nacoti M, Pesenti A. Closed system endotracheal suctioning maintains lung volume during volume-controlled mechanical ventilation. Intensive Care Med 2001;27(4):648-654

20. Branson RD. Secretion management in the mechanically ventilated patient. Respir Care 2007;52(10):1328-1347.

21. Ntoumenopoulos G. Mucus on the move: embed it or expel it: the patient, the clinician, and now the ventilator. Respir Care 2008; 53(10): 1276-1279.

22. Thompson L. Suctioning adults with an artificial airway: a systematic review. Joanna Briggs Institute for Evidence Based Nursing and Midwifery, 2000.

23. Marini J. Acoustic monitoring: super sonics? Crit Care 2009; 13(162):2.

24. Copnell B, Fergusson D. Endotracheal suctioning: time-worn ritual or timely intervention? Am J Crit Care 1995;4(2):100-105.

25. Granja C, Lopes A, Moreira S, Dias C, Costa-Pereira A, Carneiro A. Patients' recollections of experiences in the intensive care unit may affect their quality of life. Crit Care 2005;9(2):R96-R109.

This article is approved for Continuing Respiratory Care Education credit. For information and to obtain your CRCE

(free to AARC members) visit www.RCJournal.com

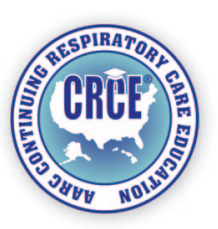

